\title{
NANOSECOND LASER DAMAGE OF METALLIC MIRRORS
}

\author{
Mihai-George MUREȘAN, Kateřina PILNÁ, Pavel ČECH, Martin MYDLÁŘ, Jan VANDA, \\ Petr NAVRÁTIL
}

HiLASE centre, Institute of Physics of the CAS, Prague, Czech Republic, EU, $\underline{\text { muresan@fzu.cz }}$

https://doi.org/10.37904/nanocon.2019.8656

\begin{abstract}
Laser surface processing is an established method to introduce surface functionalities on solid surfaces with the required throughputs for a commercial process. Fabrication of laser induced surface structures in an effective matter is done by laser interaction studies, which reveal the best processing parameters (laser wavelength, fluence, repetition, together with the processing speed and environment). Customized solutions are providing the best yields and they are being implemented faster than ever. However, the optics manufacturers are not being to keep up the pace with the new requirements, so they turn instead on older, but safer technology. In order to get a better understanding of optics capabilities, thorough testing is required. Common laser metallic mirrors, commercially available, are being rigorously tested using a nanosecond Yb:YAG laser and the results are compared with the vendor's information.
\end{abstract}

Keywords: Laser patterning, metallic mirrors, LIDT, nanosecond laser testing

\section{INTRODUCTION}

Development of laser-induced nano-structures for commercial use on metallic and dielectric surfaces faced a rapid growth in the last years [1-7], mainly due to development of powerful lasers, diffractive optics and highspeed laser scanners. To decrease the cost of mass manufacturing, users are expecting "universal" laser systems that are able to treat a wide range of materials, from polymers to metals and dielectrics. This is not an easy task for the companies producing the laser systems, since they require different parameters (wavelength, pulse duration and repetition rate) for the multitude of surfaces that are to be treated. One solution is to create a base laser system where one can add modules, which would alter/tune the laser parameters [8] closer to the requirements of treated materials. This solution is to use powerful nanosecond laser systems, which can be later altered using higher-harmonics generation and pulse compression. The powerful nanosecond laser system would require high-quality optics, which would be able to withstand the energy densities with low maintenance. The other solution will be to use a more rigid laser architecture, where only one pulsed duration and wavelength could be used, using high-cost dedicated dielectric coatings for its optics The metrology of these components, the so called laser-induced damage threshold (LIDT) testing is starting to be very important from the application point of view since can provide additional information for lifetime expectancy of different optics.

For the LIDT measurement, two commercial metallic mirrors were selected for their broadband reflectance, affordability and known structure (as opposed to dielectric). The mirrors were tested using a 1-on-1 and N-on1 methodology, according to ISO 21254-1:4, while Bivoj laser system (10 ns, $10 \mathrm{~Hz}, 1030 \mathrm{~nm}$ ) [9]. The LIDT results were discussed for each methodology and compared with the producer's information publicly available.

\section{EXPERIMENT SETUP}

The measurement was performed in Class 7 clean room, with controlled environment, in HiLASE centre [10], as described in the Figure 1. Samples were tested in accordance with the ISO 21254-1:4 protocols, using 1-on-1 and S-on-1 procedure. Camera based damage detection was used in situ while a confocal laser 
microscope performed the post mortem check. Damage threshold value was defined at zero damage probability level by linear extrapolation.

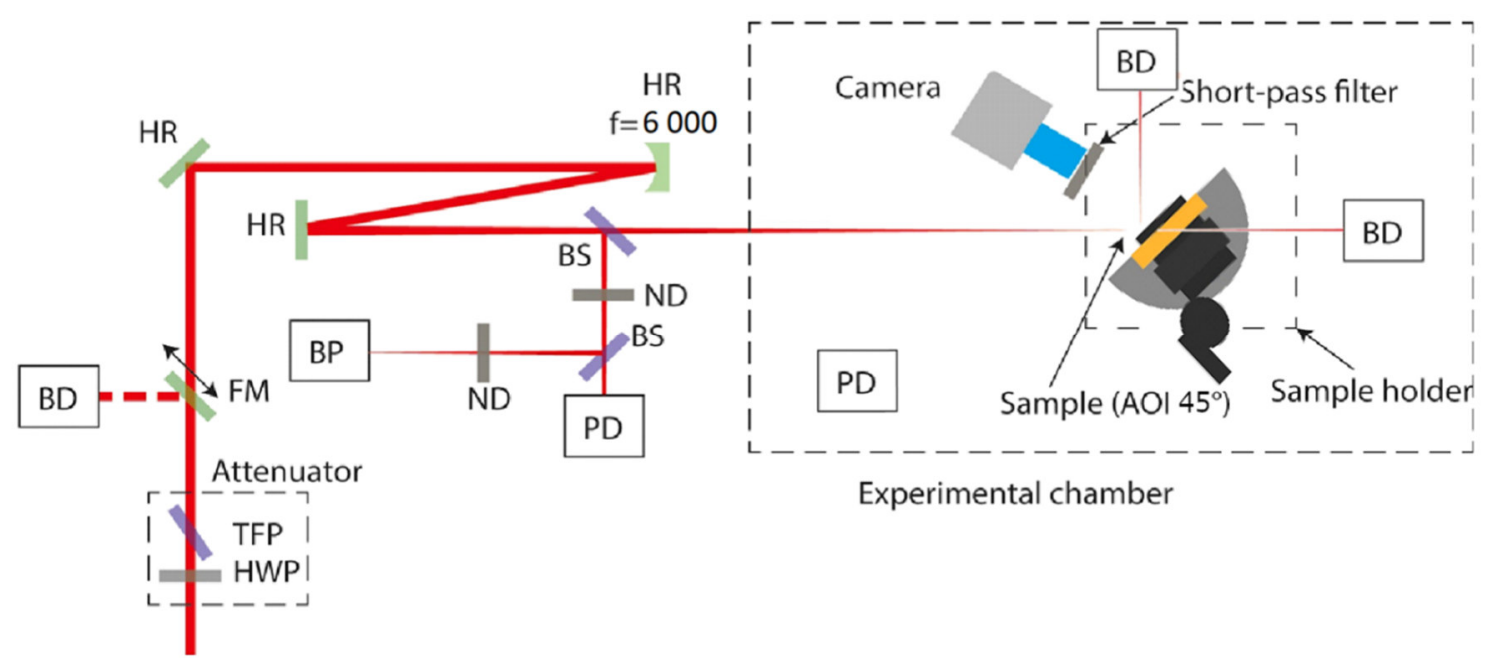

Figure 1 Experimental arrangement for LIDT testing: HWP - half wave plate, TFP - thin film polarizer, FM - fast mirror (flipper), BD - beam dump, HR - high reflective mirror, BS - beam sampler, ND - neutral density filter, PD - fast photodiode, BP - CMOS-based camera for beam profiling

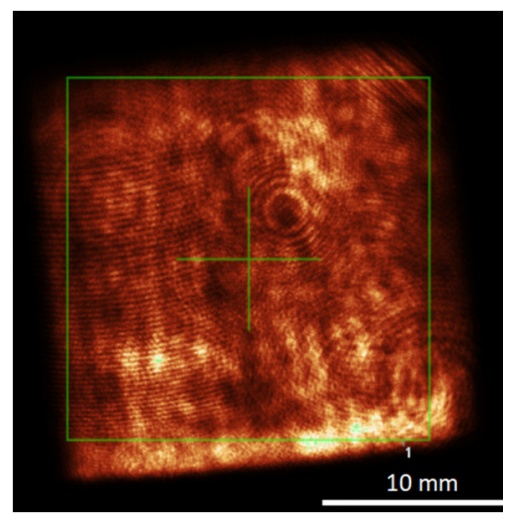

a)

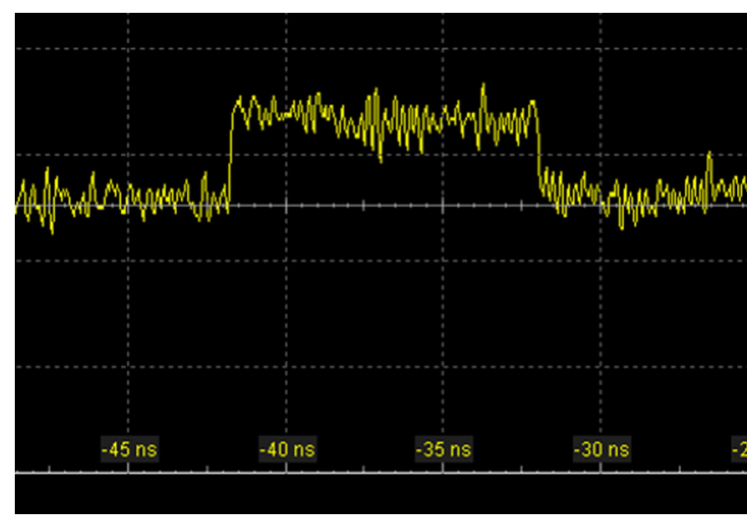

b)



c)

Figure 2 Spatial profile of the laser beam: a) - 2D beam profile in the nearfield, b) - temporal profile and c) - Gaussian profile (color distribution) of the laser beam in the target plane

Two metallic (Au and Ag) 2" mirrors, commercially available, which also had information related to the LIDT values, were selected for the task. Both mirrors are used in wide range of laser systems due to their low cost and wide reflectance range. The gold mirror is capable if reflecting in NIR (near infrared) and IR Ravg $>96 \%$ from $800 \mathrm{~nm}$ to $20 \mu \mathrm{m}$ which make it almost universal. The silver mirror has better characteristic in the visible part, being able to reflect almost down to UV region $R_{\text {avg }}>97.5 \%$ for $450 \mathrm{~nm}-2 \mu \mathrm{m}$ which is very useful when using laser systems with higher harmonics generation. The IR reflectance was similar with the one of gold mirror $\mathrm{R}_{\mathrm{avg}}>96 \%$ for $2-20 \mu \mathrm{m}$. Both mirrors came in "protected" version - a thin $\mathrm{SiO}_{2}$ overcoat was used to protect the soft metallic surfaces from scratches, which might appear during cleaning process. The vendor states LIDT values for the mirrors as $2 \mathrm{~J} / \mathrm{cm}^{2}$ and $3 \mathrm{~J} / \mathrm{cm}^{2}$ for gold and respectively silver mirrors. The specified test parameters are not complete, stating only the wavelength, pulse duration, repetition rate and beam diameter $(1064 \mathrm{~nm}, 10 \mathrm{~ns}, 10 \mathrm{~Hz}, \varnothing 1.000 \mathrm{~mm}$ ). Other important parameters such as number of pulses, distance between two irradiated sites was also not mentioned in the test details. 


\section{LIDT RESULTS AND DISCUSSION}

Our laser parameters are very close to those used by the manufacturer, 1030 vs $1064 \mathrm{~nm}$ same pulse width and repetition rate and smaller beam diameter 650 vs $1000 \mu \mathrm{m}$ (Figure 2c). The exact test procedure used by the manufacturer was not available, so a wide range of test would be more relevant. The traditional 1-on-1 testing gives the highest LIDT values, which are decreasing with the number of pulses. Our target was to use an $\mathrm{N}$-on-1 procedure, where $\mathrm{N}=1,10$ and 100 pulses (Figure 3 ) trying to cover as much as possible of the eventual measurement ranges. The LIDT results are very similar for both samples, but much lower than expected (Table 1). Even if we take the 1-on-1 testing, which achieved the highest LIDT value; our results are well below the $50 \%$ of declared values. The particularity of the silver mirror can be seen in the results presented in Figure $\mathbf{3 b} \mathbf{b} \mathbf{d}$ and $\mathbf{f}$ where one can notice the scattering of the damage probability points. This is a characteristic mark of small damages which cannot be detected in situ by due to insufficient magnification of the objective, but are visible when the sample is scanned (post mortem) using the confocal microscope. A bigger testing surface would be required to provide better statistics, but that would deform de test results, since it is obvious that polishing and coating of bigger substrates poses greater challenges than smaller ones.

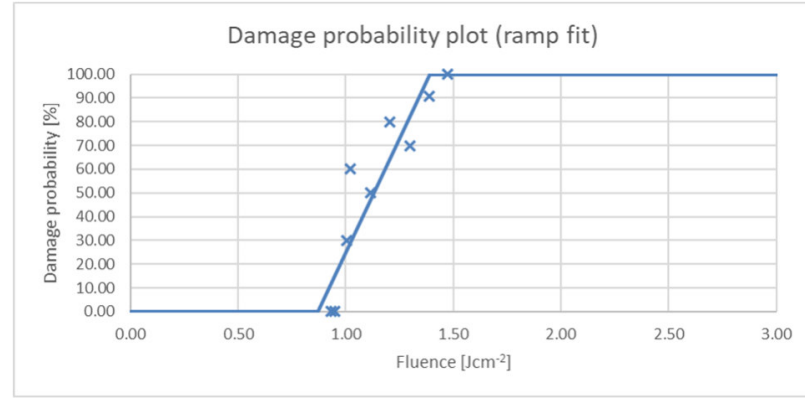

a) Au mirror 1-on-1

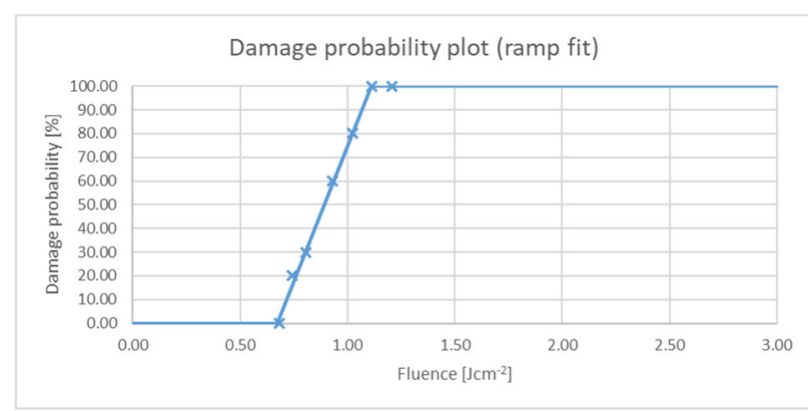

c) Au mirror 10-on-1



e) Au mirror 100-on-1



b) Ag mirror 1-on-1



d) Ag mirror 10-on-1

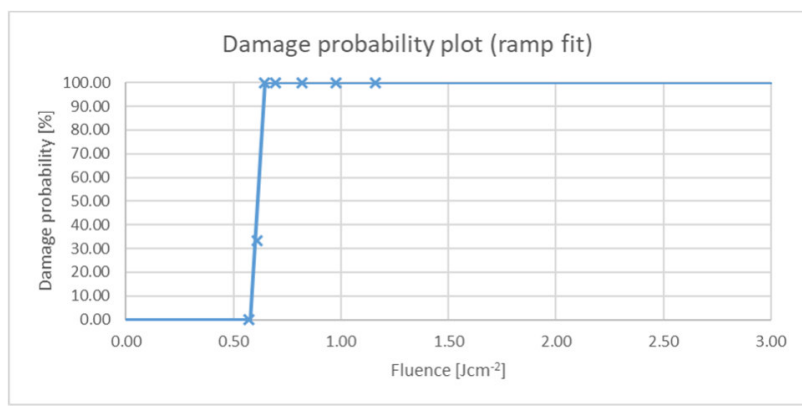

f) Ag mirror 100-on-1

Figure 3 Damage probabilities for gold and silver mirrors in regards to the pulse count 
Table 1 LIDT results for gold and silver mirrors, compared with manufacturer's declared value

\begin{tabular}{|c|c|c|c|c|}
\hline & $\begin{array}{c}1-o n-1 \\
\left(\mathbf{J} / \mathbf{c m}^{2}\right)\end{array}$ & $\begin{array}{c}10-\text { on-1 } \\
\left(\mathbf{J}^{2} \mathbf{c m}^{2}\right)\end{array}$ & $\begin{array}{c}\text { 100-on-1 } \\
\left(\mathbf{J} / \mathbf{c m}^{2}\right)\end{array}$ & $\begin{array}{c}\text { Manufacturer LIDT } \\
\left(\mathbf{J} / \mathbf{c m}^{2}\right)\end{array}$ \\
\hline Au protected mirror & 0.86 & 0.67 & 0.60 & 2.00 \\
\hline Ag protected mirror & 0.81 & 0.83 & 0.57 & 3.00 \\
\hline
\end{tabular}

Looking at the damage sites morphology, we can see distinct patters for the two mirrors. On 1-on-1 test (Figure 4a), the gold mirror has well defined damage crater, with a visible $\mathrm{SiO}_{2}$ and $\mathrm{Au}$ thin films separation. This is a mark of dielectric removal. By increasing the number of pulses on the site, it is possible to see the gold film melting and removal up to the substrate (Figure 4 b-c).

Crater morphology in silver mirrors (Figure 4e) shows a tendency to delaminate over wider ranges than irradiated. This could be a signal of stressed films, which are not managing the extra compressive wave of the laser. In Figure 4 e-f are visible delamination around the test site. It looks like the pressure wave creates a liftoff effect on the nearby areas. Perhaps issues with silver adhesion needs to be solved during the manufacturing process.

Trying to deeply understand the issue, we are looking at different manufacturers to see what their results are and we find out that another one is declaring 0.8 and $0.5 \mathrm{~J} / \mathrm{cm}^{2}$ for gold and silver mirrors. Looking at the third vendor, the LIDT values are 0.9 and $1.8 \mathrm{~J} / \mathrm{cm}^{2}$ for the same mirror type. It seems that there is an agreement on a value of $0.8 \mathrm{~J} / \mathrm{cm}^{2}$ for protected gold mirror, similar with our findings. The silver mirrors seem not to be fully in agreement with our results, with values ranging from 0.5 to $1.8 \mathrm{~J} / \mathrm{cm}^{2}$. Perhaps the oxidation/tarnishing of the silver coating has a higher impact than the quality of the thin film. All manufacturer recommends extra care when handling the silver mirrors, low humidity environment being preferred. Although our laboratory conditions are fulfilling those criteria $\left(21^{\circ} \mathrm{C}, \mathrm{RH}<40 \%\right)$, during the storage and experiment, we cannot envisage the manufacturer's storage and transport conditions.

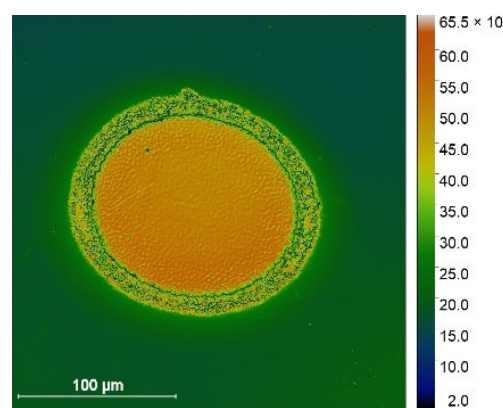

a) Au 1-on-1



d) Ag 1-on-1

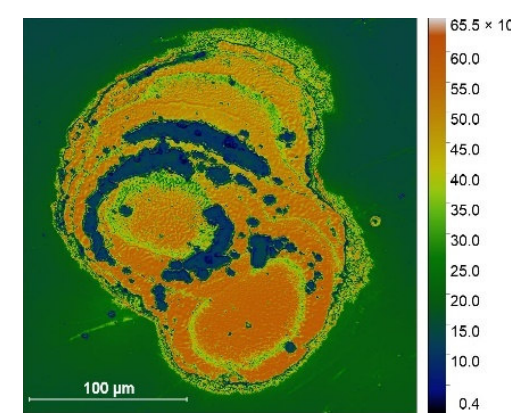

b) Au 10-on-1



e) Ag 10-on-1

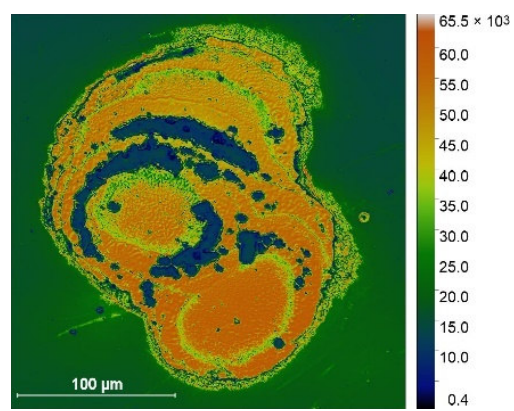

c) Au 100-on-1

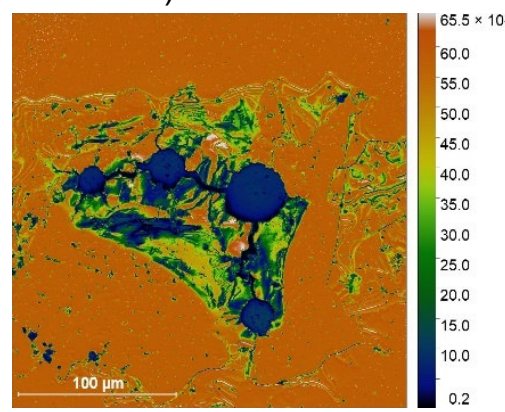

f) $\mathrm{Ag} \mathrm{100-on-1}$

Figure 3 Laser confocal microscopy images of the damaged sites (top row - gold mirror and bottom one silver mirror) 


\section{CONCLUSION}

The selection of quality optics for surface processing using laser beams is not a trivial task. It seems like a poor understanding of the LIDT standard, meaning of its values and conversion of those data into useful info for application area can create issues. It is not clear whether the all vendors are performing LIDT tests according to the ISO 21254-1:4 recommendations, since most of the tests details are not available. Care needs to be taken in account from the moment of optics delivery, where microscope inspection should be necessary. This step will eliminate any undesirable aging effects of certain components used for high-energy/high-power applications. Proper testing, using as much as possible a laser source similar if not identical to one intended, would eliminate much of the uncertainties, allowing for safer usage of laser systems and thus creating the context for smaller, highly ordered, fast produced surface nanostructure.

\section{ACKNOWLEDGEMENTS}

Funding: This work was supported by European Structural and Investing Funds, Operational Programme Research, Development and Education (Grant agreement NO CZ.02.1.01/0.0/0.0/15_006/ 0000674) and from the European Union's Horizon 2020 research and innovation programme (Grant agreement NO 739573).

\section{REFERENCES}

[1] CLAIS, Daniel, MUCKLICH, F. and ZHONGFAN Liu. Periodical Micro-Nano-Structuring of Metallic Surfaces by Interfering Laser Beams, Applied Surface Science. 2003. vol. 208. pp. 317-321.

[2] JUODKAZIS, Saulius, MIZEIKIS, Vygantas, MATSUO, Shigeki, UENO, Kosei and MISAWA, Hiroaki. ThreeDimensional Micro- and Nano-Structuring of Materials by Tightly Focused Laser Radiation. Bulletin of the Chemical Society of Japan. 2008. vol. 81. pp. 411-448.

[3] KOLACEK, K., STRAUS, Jaroslav, SCHMIDT, J., FROLOV, Alexandr, PRUKNER, Václav, SHUKUROV, A., HOLY, Vaclav, SOBOTA, J. and FORT, T. Nano-structuring of solid surface by extreme ultraviolet Ar8+ laser. Laser and Particle Beams. 2012. vol. 30. pp. 57-63.

[4] ZAVESTIVSKAYA, I. Laser nanostructuring of materials surfaces. Quantum Electronics. 2010. vol. 40. pp. 942954.

[5] FRAGGELAKIS, Fotis, MINCUZZI, Girolamo, LOPEZ, John, MANEK-HONNINGER, Inka and KLING, Rainer. Controlling 2D laser nano structuring over large area with double femtosecond pulses. Applied Surface Science. 2018. vol 470. pp. 677-686. 10.1016/j.apsusc.2018.11.106.

[6] HAUSCHWITZ, Petr, R., Jagdheesh, ROSTOHAR, Danijela, BRAJER, Jan, KOPECEK, J., JIRICEK, Petr, HOUDKOVA, J. and NEJDL, Jaroslav. Nanostructure fabrication on the top of laser-made micropillars for enhancement of water repellence of aluminium alloy. Materials Letters. 2019. vol. 256. pp. 126601.

[7] R, Jagdheesh, HAUSCHWITZ, Petr, MUZIK, Jiri, BRAJER, Jan, ROSTOHAR, Danijela, JIRICEK, Petr, KOPECEK, J., and NEJDL, Jaroslav. Non-fluorinated superhydrophobic Al7075 aerospace alloy by ps laser processing. Applied Surface Science. 2019. vol. 493. pp. 287-293.

[8] SMRZ, Martin, NOVAK, O., MUZIK, Jir, TURCICOVA, H., CHYLA, Michal, NAGISETTY, S.S., VYVLECKA, M., ROSKOT, Lukáš, MIURA, T., CERNOHORSKA, Jitka, SIKOCINSKI, Pawel, CHEN, Liyuan, HUYNH, Jaroslav, KRUPICKOVA, P., PRANOVICH, Alina, ENDO, A., and NEJDL, Jaroslav. Advances in high-power, Ultrashort pulse DPSSL technologies at HiLASE. Applied Sciences. 2017. vol. 7. pp. 1016.

[9] MASON, Paul, DIVOKY, Martin, BUTCHER, Thomas, PILAR, Jan, ERTEL, Klaus, HANUS, Martin, DE VIDO, Mariastefania, BANERJEE, Saumyabrata, PHILLIPS, Jonathan, SMITH, Jodie, HOLLINGHAM, Ian, MURESAN, Mihai-George, LANDOWSKI, Brian, SUAREZ-MERCHAN, Jorge, THOMAS, Adrian, DORMINEY, Mark, BENSON, Luke, LINTERN, Andrew, COSTELLO, Billy and COLLIER, John. Commissioning of a kW-class nanosecond pulsed DPSSL operating at $105 \mathrm{~J}, 10 \mathrm{~Hz}$. Proceedings of SPIE High-Power, High-Energy, and HighIntensity Laser Technology III. 2017. vol. pp.102380H.

[10] https://www.hilase.cz/en/we-offer/services/laser-induced-damage-threshold/ 